\title{
A INFLUÊNCIA DO CAPITAL CULTURAL NA FORMAÇÃO DOCENTE
}

\author{
LA INFLUENCIA DEL CAPITAL CULTURAL EN LA FORMACIÓN
}

THE INFLUENCE OF CULTURAL CAPITAL ON TEACHER FORMATION

\author{
Andreza OLIVIERI LOPES CARMIGNOLLI ${ }^{1}$ \\ Luci Regina MUZETTI ${ }^{2}$ \\ Laís Inês SANSEVERINATO MICHELETI ${ }^{3}$
}

RESUMO: O trabalho realizado analisou como o capital cultural, definido por Pierre Bourdieu, está relacionado com a constituição do éthos; a relação entre a função docente e o status conferido ao exercício da profissão, enquanto estratégia de ascensão social. Os estudos de Carlindo (2009), Pies (2011) e Lima (2013) mostram que no espaço escolar o éthos é observado pela maneira como o professor transmite o conhecimento e as relações construídas entre a cultura escolar e o conhecimento produzido. Utilizamos os estudos de Pierre Bourdieu como referencial teórico para a conceitualização de habitus, éthos, capital cultural, capital social, capital econômico e estratégias de reprodução. O trabalho foi feito com base em uma abordagem qualitativa, tendo como recurso metodológico a análise documental e o estudo de caso, através da observação da prática docente.

PALAVRAS-CHAVE: Éthos. Capital cultural. Formação docente.

RESUMEN: El trabajo realizado ha analizado cómo el capital cultural, definido por Pierre Bourdieu, está relacionado con la constitución del éthos; la relación entre la función docente y el estado conferido al ejercicio de la profesión, como estrategia de ascensión social. Los estudios de Carlindo (2009), Pies (2011) y Lima (2013) muestran que en el espacio escolar el éthos es observado por la manera como el profesor transmite el conocimiento y las relaciones construidas entre la cultura escolar y el conocimiento producido. Utilizamos los estudios de Pierre Bourdieu como referencia teórica para la conceptualización de habitus, éthos, capital cultural, capital social, capital económico y estrategias de reproducción. El trabajo se realizó sobre la base de un enfoque cualitativo utilizando como recurso metodológico el análisis documental y el estudio de caso, a través de la observación de la práctica docente.

PALABRAS CLAVE: Éthos. Capital cultural. Formación docente.

\footnotetext{
1 Universidade Estadual Paulista (UNESP), Araraquara - SP - Brasil. Doutoranda do Programa de PósGraduação em Educação Escolar. ORCID: https://orcid.org/0000-0001-5593-9793. E-mail: andreza.o.carmignolli@unesp.br

${ }^{2}$ Universidade Estadual Paulista (UNESP), Araraquara - SP - Brasil. Professora Livre Docente em Sociologia no Departamento de Didática e Professora do Programa de Pós-Graduação em Educação Escolar. Doutorado em Educação (UFSCAR). ORCID: https:// orcid.org/0000-0002-6808-2490. E-mail: luci.muzzeti@unesp.br

3 Universidade Estadual Paulista (UNESP), Araraquara - SP - Brasil. Mestranda do Programa de PósGraduação em Educação Escolar. Bolsista da CAPES. ORCID: https://orcid.org/0000-0002-2748-3407. E-mail: lais.ines@outlook.com
} 
ABSTRACT: The work analyzed how the cultural capital, defined by Pierre Bourdieu, is related to the constitution of the éthos; the relation between the teaching function and the status conferred to the practice of the profession, as a strategy of social ascension. The studies by Carlindo (2009), Pies (2011) and Lima (2013) show that in the school space, éthos is observed through the way the teacher transmits the knowledge and the relations built between the school culture and the knowledge produced. We used the studies of Pierre Bourdieu as a theoretical reference for the conceptualization of habitus, éthos, cultural capital, social capital, economic capital and reproduction strategies. The work was based on a qualitative approach using documentary analysis and case study as a methodological resource, through observation of teaching practice.

KEYWORDS: Éthos. Cultural capital. Teacher education.

\section{Introdução}

Nos dias atuais, conforme destaca Bourdieu (2003), a escola é um fator de mobilidade social, que age sobre todo o processo de ensino, legitimando o mecanismo de apreender nos diversos graus de desenvolvimento. Nesse processo, a família é responsável por transmitir a seus filhos uma parte do capital cultural e um certo éthos.

O éthos é definido por valores implícitos e interiorizados, que contribuem na definição de atitudes face ao capital cultural e à instituição escolar. Desta forma, a transmissão do capital cultural é produto do nível cultural global da família e do êxito escolar. A ação do meio familiar sobre o êxito escolar é exclusivamente cultural. O nível de instrução dos membros da família é um indicador que permite situar o nível cultural de cada família.

O papel da escola em relação à contribuição do capital cultural adquirido no meio familiar para a constituição do êxito nas diferentes frações de classe é marcado pelo espaço social, em que os agentes têm pontos de vista conforme a posição por eles ocupada, exprimindo sua vontade de transformá-los ou conservá-los.

A instituição escolar, ao desempenhar a função que lhe cabe, proporciona a todos os membros da sociedade o desenvolvimento de práticas culturais consideradas mais nobres, entre as quais destacamos as habilidades estruturantes do processo de ensino aprendizagem, como a aquisição da leitura, da escrita e do cálculo.

De acordo com os estudos de Bourdieu (1992), as estruturas de funcionamento do sistema de ensino são caracterizadas pelos próprios meios de produção e reprodução, conforme as condições institucionais, sendo que as relações entre os grupos ou as classes contribuem para a reprodução social. 
É importante destacar que as diferentes aprendizagens escolares são fruto de uma trajetória escolar sem fracassos e interrupções por meio de uma familiarização com a cultura e com a linguagem, exigindo que os agentes possuam os códigos necessários para a apreensão da cultura dominante.

Podemos observar essa apreensão por meio da ascensão social através da trajetória escolar de estudantes do curso de Pedagogia da UNIARA, a partir da análise das condições de escolarização básica até a escolha do curso superior (REINA; MUZZETI; MARGONARI, 2017). Esse artigo destaca a importância do papel da instituição de ensino superior na política de acesso e permanência de alunos com poder econômico desfavorecido e a preocupação com a formação dos futuros professores.

Aqui temos um exemplo claro de duas modalidades do capital cultural, a primeira é o estado incorporado onde foi observada transformação na maneira de falar dessas alunas após seu ingresso e convívio com outros alunos dentro da universidade; a segunda é o estado institucionalizado através da conclusão do curso e recebimento do diploma.

\section{Referencial teórico}

No contexto escolar, os projetos são considerados um facilitador na construção da aprendizagem significativa por meio da participação ativa dos professores e alunos num processo mútuo de troca de informações e experiências, sendo que ambos estão inseridos no processo de aquisição do conhecimento de maneira significativa e prazerosa (LEITE, 2007).

Solé (1999), explica que durante as situações de ensino e aprendizagem ocorrem interações entre professores e alunos, propiciando a construção de motivações intrínsecas, as quais são fundamentais no processo de ensino.

Segundo a autora, o processo de ensino pressupõe uma mobilização cognitiva, desencadeada pelo interesse ou necessidade do aluno para a realização da atividade proposta. Desta maneira a tarefa de aprendizagem deve constituir um desafio para o aluno, algo que ainda não construiu e que, de acordo com suas possibilidades, irá adquirir na aquisição de novos conhecimentos.

A pesquisa de Carvalho (2013) mostra que o uso de atividades diferenciadas, através do uso do blog e de aulas experimentais, é capaz de despertar a curiosidade dos alunos, favorecendo a construção do conhecimento. Mas destaca a importância da formação continuada dos professores que norteará o planejamento de atividades diferenciadas e a 
utilização de estratégias de ensino para atender os diferentes ritmos de aprendizagem, conforme as possibilidades sociais e econômicas do espaço escolar.

\section{Metodologia}

O trabalho foi desenvolvido com base na metodologia praxiológica, uma vez que se relaciona interna e externamente com a apreensão do sujeito para a estruturação do habitus, com abordagem qualitativa. O tipo de pesquisa realizada foi o estudo de caso dentro de uma unidade escolar pertencente à diretoria de ensino da cidade de Araraquara/SP, por meio de conversas com professores e observação das atividades aplicadas em sala.

Inicialmente, selecionamos uma escola da rede estadual de ensino de Araraquara para desenvolvimento do projeto. Optamos em trabalhar com uma escola de ensino fundamental, com a intenção de acompanharmos as reuniões de ATPC (Atividade de Trabalho Pedagógico Coletivo) e os resultados obtidos nos processos de avaliações educacionais para adequações das práticas pedagógicas docentes utilizadas em sala de aula, objetivando a melhoria do processo de ensino-aprendizagem. Além disso, foram realizadas observações das práticas pedagógicas utilizadas pelos docentes, procurando investigar o que norteia o planejamento das atividades didáticas e como são planejadas as ações pedagógicas.

\section{Análise e discussão}

Atualmente observamos que o quadro de professores dos anos iniciais é composto por mulheres, talvez pela relação desses primeiros anos de escolarização se relacionar com a figura maternal, ou seja, do cuidar, ensinar as primeiras lições, zelar pela aprendizagem da leitura e da escrita e o contato com a instituição escolar.

No início dos anos setenta o magistério era a única profissão que conciliava as funções domésticas da mulher, ou seja, o papel do cuidar representado pela figura feminina que naquele momento foi utilizado para solução do problema da falta de mão-de-obra nas escolas primárias (TANURI, 2000, p. 66). Foi o que observamos ao levantarmos a trajetória de formação dessas docentes, que para uma grande parte, a escolha da profissão foi influenciada pelo momento histórico.

A partir do ano 2009 os cursos de formação de professores para exercer a docência nos anos iniciais de ensino passaram a seguir as instruções do artigo 62 da Lei de Diretrizes e Bases da Educação Nacional (LDBEN/1996), que trata como obrigatório para o exercício 
docente nos anos iniciais uma formação superior, com o intuito de melhorar a qualidade da educação básica. Mas vale destacar que uma das metas do Plano Nacional de Educação (PNE) prevê que até 2020 todos os professores deste segmento de ensino tenham formação superior.

Segundo os autores Darius e Darius (2018), o século XX deixou legados positivos e negativos nas transformações educacionais, mostrando em seus estudos que a educação por si só não tem a primazia sobre os problemas sociais, mas a defesa de uma escola pública democrática e de boa qualidade àqueles que necessitam dela para o acesso ao saber.

$\mathrm{Na}$ unidade escolar que o trabalho foi desenvolvido o quadro docente era composto por vinte professoras e todas tinham o curso superior. Optamos em trabalhar com as professoras alfabetizadoras, ou seja, professoras do primeiro ao terceiro ano de ensino, totalizando doze professoras.

Quadro 1 - Número de docentes e ano em que lecionam

\begin{tabular}{|c|c|}
\hline Número de docentes & Turma que leciona \\
\hline 4 & $1^{\circ}$ ano \\
\hline 4 & $2^{\circ}$ ano \\
\hline 4 & $3^{\circ}$ ano \\
\hline 4 & $4^{\circ}$ ano \\
\hline 4 & $5^{\circ}$ ano \\
\hline
\end{tabular}

Fonte: dados da pesquisa.

A análise da formação dessas professoras mostrou que uma professora do primeiro ano tinha o magistério e depois concluiu seus estudos superiores em Letras e, uma do terceiro ano também tinha o magistério e no ano de 2009 fez a faculdade de Normal Superior e apenas uma professora do quarto ano tinha apenas o magistério.

Retomando nosso público de pesquisa, ou seja, as professoras dos anos iniciais de escolarização, verificamos que as meninas ao concluírem o ensino secundário, a antiga oitava série, iam cursar o magistério e as que tinham um capital econômico mais privilegiado, e um sucesso escolar, ao terminarem o magistério ingressavam no curso de Pedagogia da Faculdade de Filosofia, Ciências e Letras de Araraquara/UNESP.

Uma das professoras nos relatou que na época não existia o que hoje chamamos de professoras eventuais ou professoras substitutas, as professoras ao se formarem em Pedagogia exerciam um estágio remunerado até conseguirem ingressar na carreira docente e ter uma "cadeira", se efetivar.

Outra apontou que esse estágio era difícil de conseguir e que eram na base da insistência, vínculos de amizades ou apadrinhamentos que conseguiam estagiar, caso 
contrário, para ajudar na renda familiar, tinham que trabalhar como vendedoras no comércio local até ingressarem na carreira.

A escolha da profissão docente estava ligada a ser um curso destinado quase que exclusivamente as mulheres e pela facilidade de a faculdade ser na própria cidade, pois, para a maioria, as condições econômicas eram precárias; nessa época as mulheres não precisavam se formar, pois iriam casar e cuidar dos afazeres domésticos e da criação dos filhos. Apenas os filhos homens teriam que ter uma instrução superior, pois a eles caberia o sustento familiar.

Então aqui percebemos que o capital cultural se distinguia na forma do diploma, ou seja, as famílias que tinham um maior capital econômico investiam também nos estudos das filhas, oferecendo-lhes uma oportunidade também de um matrimônio melhor, pois frequentando um espaço acadêmico arranjariam pretendentes mais cultos, ou seja, que possuíam uma formação superior mantendo assim um mesmo nível cultural, econômico e social, permanecendo na mesma fração de classe ou ascendendo socialmente através do diploma.

Isto nada mais é o que Seidl (2017, p. 191) explica como uma estratégia de reprodução em relação aos recursos disponíveis de investimento a uma determinada atividade, neste caso a da docência; as docentes participantes desse trabalho são oriundas de uma fração de classe detentoras de um capital econômico menos favorecido e desta maneira foi através do capital cultural que tiveram oportunidade de ascenderem socialmente.

\section{Considerações finais}

O status conferido à profissão docente foi adquirido ao longo do tempo por meio de uma trajetória que abarcou variáveis como: o habitus que influenciou na representatividade de cada professora; o capital cultural institucionalizado por meio da obtenção do diploma, sendo um diferencial em relação a formação materna como observamos durante esse trabalho; a prática docente observada na maneira de transmissão do conhecimento, onde notamos que as professoras reproduziam as práticas docentes as quais vivenciaram quando alunas, principalmente, na maneira de alfabetizar através das famílias silábicas. E outro fator interessante em relação a esse grupo é que todas tiveram uma trajetória ascendente.

Para Brito (2017, p. 355) essas variáveis revestem uma variedade de diferenças singulares que levam em conta não apenas seu ponto de origem, mas também a influência das linhagens às quais cada indivíduo pertence. 
Concluímos assim que o ingresso no ensino superior, naquele momento histórico, proporcionou a essas professoras um futuro promissor e ao mesmo tempo um compromisso com a postura docente frente ao conhecimento a ser transmitido; pois este estará ligado à maneira como o aluno irá incorporar esse conhecimento.

AGRADECIMENTOS: O presente trabalho foi realizado com apoio da Coordenação de Aperfeiçoamento de Pessoal de Nível Superior - Brasil (CAPES) - Código de Financiamento 001.

\section{REFERÊNCIAS}

BOURDIEU, P. Espaço social e poder simbólico. In: BOURDIEU, P. Coisas ditas. Trad. C. R. da Silveira e D. M. Pegorim. São Paulo: Brasiliense, p. 149-168, 1992.

BOURDIEU, P. A Escola Conservadora: as desigualdades frente à escola e à cultura. In: BOURDIEU, P. Escritos da Educação. Petrópolis: Vozes, p. 41-64, 2003.

BRITO, A. X. Trajetória. In: CATANI, A. M. et al. (Orgs.). Vocabulário Bourdieu. Belo Horizonte: Autêntica Editora, p. 354-356, 2017.

CARLINDO, E. P. Tornar-se professora: o capital cultural como esteio explicativo para o sucesso docente. 2009. 135 f. Dissertação (Mestrado em Educação Escolar) - Universidade Estadual Paulista, Faculdade de Ciências e Letras de Araraquara, 2009. Disponível em: http://hdl.handle.net/11449/90247. Acesso em: 22 jun. 2020.

CARVALHO, P. S. O uso de blogs e aulas experimentais como práticas educativas no ensino de físico-química para o ensino médio: um estudo descritivo a partir do conceito de aprendizagem significativa. 2013. 122 f. Dissertação (Mestrado em Ensino de Ciências e Matemática) - Universidade Federal do Ceará, Centro de Ciências, Fortaleza, 2013.

DARIUS, R. P. P.; DARIUS, F. A. A educação pública no Brasil no século XX:

considerações à luz da formação dos grupos escolares e do manifesto dos pioneiros da educação nova. Doxa: Revista Brasileira de Psicologia e Educação, Araraquara, v. 20, n. 1, p. 32-41, jan./jun., 2018. e-ISSN: 2594-8385. Disponível em:

https://periodicos.fclar.unesp.br/doxa/article/view/11248/7385. Acesso em: 22 jun. 2020.

DOI: https://doi.org/10.30715/rbpe.v20.n1.2018.11248

LEITE, L. H. A. Pedagogia de projetos e projetos de trabalho. Presença Pedagógica, Belo Horizonte: Dimensão, v. 73, p. 62-69, 2007.

PIES, N. G. Capital cultural e educação em BOURDIEU. 2011. 69 f. Dissertação (Mestrado em Educação) - Universidade de Passo Fundo, Passo Fundo, 2011.

REINA, F. T.; MUZZETI, L. R.; MARGONARI, D. M. Trajetórias escolares: a pedagogia da UNIARA como possibilidade de ascensão aos níveis superiores e de profissionalização de alunos das camadas populares. Temas em Educação e Saúde, [S.1.], v. 10, p. 37-44, mar. 
2017. ISSN 2526-3471. Disponível em: https://periodicos.fclar.unesp.br/tes/article/view/9613. Acesso em: 22 jun. 2020. DOI: https://doi.org/10.26673/tes.v10i0.9613

SEIDL, E. Estratégia/estratégias de reprodução. In: CATANI, A. M. et al. (Orgs.).

Vocabulário Bourdieu. Belo Horizonte: Autêntica Editora, p. 189-191, 2017.

SOLÉ, I. Disponibilidade para a aprendizagem e sentido da aprendizagem. In: COLL, C. et al. O construtivismo na sala de aula. 6. ed. São Paulo: Ática, 1999.

TANURI, L. M. História da formação de professores. Revista Brasileira de Educação, Rio de Janeiro, n. 14, p. 62-88, maio/jun./jul./ago. 2000.

\section{Como referenciar este artigo}

OLIVIERI LOPES CARMIGNOLLI, A.; MUZETTI, L. R.; SANSEVERINATO MICHELETI, L. I. A influência do capital cultural na formação docente. Doxa: Rev. Bras. Psico. e Educ., Araraquara, v. 22, n. 1, p. 225-232, jan./jun., 2020. e-ISSN: 2594-8385. DOI: https://doi.org/10.30715/doxa.v22i1.13694

Submetido em: 15/02/2020

Revisões requeridas em: 30/04/2020

Aceito em: 28/05/2020

Publicado em: 01/06/2020 